\title{
Morphometrical analysis of Taenia taeniaeformis and Taenia crassiceps in the common vole (Microtus arvalis) and the water vole (Arvicola terrestris) in Vorarlberg, Austria
}

\author{
H.-P. FUEHRER ${ }^{1}$, C. SIEHS ${ }^{2}$, R. SCHNEIDER ${ }^{1}$, H. AUER ${ }^{1 *}$ \\ ${ }^{1}$ Institute of Specific Prophylaxis and Tropical Medicine, Center for Pathophysiology, Infectiology and Immunology, \\ Medical University of Vienna, Austria, E-mail: herbert.auer@meduniwien.ac.at; ${ }^{2}$ Department of Biomedical \\ Engineering, University of Applied Sciences, Technikum Wien, Hoechstaedtplatz 5, 1200 Wien, Austria
}

\begin{abstract}
Summary
Taenia taeniaeformis and Taenia crassiceps are cestodes with voles as intermediate hosts and Felidae, Canidae and Mustelidae as definitive hosts. To evaluate the influence of $T$. taeniaeformis metacestodes on voles in Vorarlberg (Western Austria), a helminthological survey was performed on 318 common voles (Microtus arvalis) and 93 water voles (Arvicola terrestris). Furthermore the metacestodes themselves were analysed by morphometric methods. Our results demonstrate that both $T$. taeniaeformis and T. crassiceps are endemic in Vorarlberg, and that there is a significant difference between those infected with larvae of $T$. taeniaeformis and uninfected voles regarding body weight, but not sex or body length.
\end{abstract}

Keywords: Taenia taeniaeformis; Taenia crassiceps; Microtus arvalis; Arvicola terrestris; morphometrics

\section{Introduction}

Taenia taeniaeformis, a cyclophyllidean cestode, is an almost worldwide distributed parasite with Felidae as the common definitive hosts. In Europe this cestode has been documented in wild cats, domestic cats and European lynx (e.g. Loos-Frank \& Zeyhle, 1982). Furthermore this parasite can be hosted by Canidae, e.g. red foxes and dogs (e.g. Pfeiffer et al., 1997), and Mustelidae. In the definitive host the adult tapeworms are located in the intestine, and can cause diarrhoea and emaciation. The gravid proglottides of this tapeworm can be found in the final host's faeces. The most important intermediate hosts are Murinae and Arvicolinae, but metacestodes were also found in Soricidae and pheasants (Phasanius colchicus) (e.g. Schmidt, 2001; Milazzo et al., 2010). Metacestodes are described as being a few millimetres in size with yellowish-white cysts (Cysticercus fasciolaris) which are located in the intermediate host's liver tissue (Schaerer, 1987). These cysts inhabit the larvae with a $5-200 \mathrm{~mm}$ long and $1-7 \mathrm{~mm}$ broad stro- bilocercus attaching to a bladder. The scolex is armed with $26-38$ hooks, of which the large hooks reach lengths of up to $400 \mu \mathrm{m}$ and the small hooks a size of $250 \mu \mathrm{m}$.

For human medicine T. taeniaeformis is of low importance, although three confirmed cases are known. In Sri Lanka and Argentina metacestodes were found in a child (Ekanayake et al. 1999) and Sterba et al. (1977) reported a case in a woman in the CSSR. Furthermore Garin et al. (2005) diagnosed a cyclophyllidean metacestode in the brain of a 38-year old Cambodian patient.

Taenia crassiceps is a parasite of carnivores: Canidae, Felidae and Mustelidae. In Europe the most common definitive hosts are red foxes, stone martens, lynx and dogs (Loos-Frank \& Zeyhle, 1981). Murinae and Arvicolinae are the most important intermediate hosts of this parasite. However, metacestodes have also been found in dogs, domestic cats and marmosets (e.g. Wünschmann et al., 2003). Metacestodes (Cysticercus longicollis) have a length of $1-6 \mathrm{~mm}$ and an armed scolex with $28-39$ hooks. Large hooks have been described with lengths between 146 and $211 \mu \mathrm{m}$ and small hooks between 114 and $170 \mu \mathrm{m}$. Metacestodes of $T$. crassiceps are located in the musculature, in the subcutis, in peritoneal and pleural cavities (Petavy et al., 2003) and rarely in the eye (Delvalle, 1989) or in the brain (Wünschmann et al. 2003). There they form sac- or bladder-like cavities where they multiply asexually with proliferation. Human infections are rare. Most infestations were reported in immunosuppressed patients (e.g. AIDS patients), where the metacestodes are located in the musculature or connective tissue. Occasionally lesions occur, which may reappear after treatment because of the proliferation ability of these metacestodes (Chermette et al., 1995). This cestode is rarely reported with other opportunistic pathogens, e.g. Pneumocystis jirovecii or Toxoplasma gondii (Klinker et al., 1992). Infections in immunocompetent persons are even more scarce. 
Arocker-Mettinger et al. (1992) found metacestodes of $T$. crassiceps in the right eye of a 15-year-old girl, where the parasite caused iridocyclitis.

\section{Material and methods}

In 2004 (September to December), 318 common voles (Microtus arvalis) and 93 water voles (Arvicola terrestris) were captured within a pest control program in the areas of Lustenau, Hohenems and Dornbirn, three towns in Vorarlberg, the westernmost province in Austria, known as an endemic area of Echinococcus multilocularis. In a previous study at the Medical University of Vienna these voles were first examined to evaluate the presence of metacestodes of the fox tapeworm in $M$. arvalis and A. terrestris; metacestodes of $T$. taeniaeformis and $T$. crassiceps were also collected (Führer et al., 2010). These metacestodes were analysed extensively within this study.

\section{Examination of the voles}

Weight and lengths of all captured voles were measured. To exclude mix-ups with Microtus agrestris species, classification of $M$. arvalis was performed during necroscopy with an inspection of the inner side of the second molars of the upper jaw. Sex determination was performed during necroscopy.

\section{Examination of Taenia taeniaeformis}

Within this study we examined 63 metacestodes of $T$. taeniaeformis, of which 23 were found in common voles and 40 detected in water voles. Cysts of T. taeniaeformis metacestodes were measured. Afterwards the cysts were opened with forceps, the metacestode was pulled out and the width and length of the strobila was analysed. The hooks on each scolex were counted using a reflected light microscope. The scolex was then cut off and bleached with a Berlese mixture (Reichenow, 1969) on a slide for 24 hours. Afterwards the hooks were measured microscopically at $100-$ 400x magnification.

Furthermore molecular biological methods (e.g. PCR, sequencing) were used to confirm species classification within the cytochrome oxidase $1(\mathrm{CO} 1)$ and the $12 \mathrm{~S}$ ribosomal RNA genes as reported previously (Kocher et al., 1989; Rodriguez-Hidalgo et al., 2002).

\section{Examination of Taenia crassiceps}

Metacestodes of $T$. crassiceps were collected in two water voles. These metacestodes were counted, measured and stained with a Berlese mixture for the counting of the hooks.

\section{Statistical analysis}

For calculating statistically significant differences regarding total body weight, total body length and sex between $T$. taeniaeformis infected and uninfected groups of each species, after calculating Levene's Test for Equality of Variances, a t-test for independent samples was calculated assuming statistical significance below a p-value of 0.05 .

\section{Results}

\section{Taenia taeniaeformis}

Metacestodes of T. taeniaeformis were detected in 22 out of 318 screened common voles and in 30 out of 93 water voles. In total 68 intact cysts were isolated and examined. All metacestode cysts were of yellowish-white colour. Three metacestodes of the common vole and two of the water vole presented everted scoleces.

In water voles metacestodes of $T$. taeniaeformis presented cysts with a diameter of $5-13 \mathrm{~mm}$ and a weight of $0.13-$ $0.52 \mathrm{~g}$. Larvae presented strobilocerci with a length of $15-$ $139 \mathrm{~mm}$ and widths between 2.5 and $5 \mathrm{~mm}$ (Table 1). Morphometric analysis of the scolex revealed the presence of $26-36$ hooks per scolex. Large hooks measured between 395 and $485 \mu \mathrm{m}$ and small hooks between 230 and $290 \mu \mathrm{m}$.

In common voles cysts of $4-8 \mathrm{~mm}$ and a weight of $0.04-$ $0.2 \mathrm{~g}$ were observed. Strobilocerci were of $7-98 \mathrm{~mm}$ length and $1.5-4 \mathrm{~mm}$ width. Each scolex presented between 26 and 34 hooks, the sizes of which varied between 350 and $435 \mu \mathrm{m}$ in the case of large hooks and between 230 and $270 \mu \mathrm{m}$ in the case of small hooks.

Table 1. Morphometrical analysis of Taenia taeniaeformis metacestodes in common and water voles

\begin{tabular}{|c|c|c|c|}
\hline & Microtus arvalis & Arvicola terrestris & Overall \\
\hline Prevalence $^{\mathrm{a}}$ & $22 / 318(6.9 \%)$ & $31 / 93(33.3 \%)$ & \\
\hline Cysts overall & 26 & 48 & 74 \\
\hline Intact cysts & 24 & 44 & 68 \\
\hline Non-intact cysts & 2 & 4 & 6 \\
\hline Intensity ${ }^{b}$ & $1-2(1.18 \pm 0.39)$ & $1-12(1.5 \pm 2.05)$ & $1-12(1.37 \pm 1.56)$ \\
\hline Cyst length $(\mathrm{mm})^{b}$ & $4-9(7.04 \pm 1.33)$ & $5-13(8.26 \pm 1.79)$ & $4-13(7.8 \pm 1.73)$ \\
\hline Cyst width $(\mathrm{mm})^{\mathrm{b}}$ & $3-9(5.91 \pm 1.59)$ & $4-9(7.43 \pm 1.21)$ & $3-9(6.87 \pm 1.54)$ \\
\hline Strobila length $(\mathrm{mm})^{b}$ & $7-98(30.5 \pm 20.17)$ & $15-139(48.5 \pm 28.37)$ & $7-139(35.5 \pm 27.09)$ \\
\hline Strobila width $(\mathrm{mm})^{b}$ & $1.5-4(2.4 \pm 0.58)$ & $2.5-5(3.5 \pm 0.58)$ & $1.5-5(3.13 \pm 0.77)$ \\
\hline Hooks ${ }^{b}$ & $26-34(30.4 \pm 2.33)$ & $26-36(29.9 \pm 2.43)$ & $26-36(30.04 \pm 2.39)$ \\
\hline \multirow[t]{2}{*}{ Large hooks $(\mu \mathrm{M})^{b}$} & $315-435$ & $340-485$ & $315-485$ \\
\hline & $(406.1 \pm 35.61)$ & $(443.8 \pm 26.5)$ & $(430.2 \pm 34.9)$ \\
\hline \multirow[t]{2}{*}{ Small hooks $(\mu \mathrm{M})^{b}$} & $205-270$ & $220-290$ & $205-290$ \\
\hline & $(252.1 \pm 17.66)$ & $(261.6 \pm 13.9)$ & $(258.2 \pm 15.9)$ \\
\hline
\end{tabular}

${ }^{\mathrm{a}}$ Number (Percent) of voles infested.

${ }^{\mathrm{b}}$ Minimum-Maximum (Mean intensity $\pm \mathrm{SD}$ ) 
The hooks, strobilae and cysts were smaller in common voles than in water voles.

In total 34 metacestodes of $T$. taeniaeformis were analysed with Taenia-specific PCRs (CO1 and/or 12 rRNA). Species classification was confirmed by sequencing of two isolates (JN882300 and JN882301).

\section{Taenia crassiceps}

Those 318 common voles and 93 water voles were further examined for the presence of $T$. crassiceps. Metacestodes were only found in two water voles (31 and 43 larvae each) captured in Hohenems. Of those, 15 metacestodes from each vole $(n=30)$ were examined in this study. Metacestodes of $T$. crassiceps had lengths between 1.5 and 4.5 $\mathrm{mm}$. The scolex presented between 28 and 36 hooks, of which the large hooks were sized between 150 and $192 \mu \mathrm{m}$ and the small hooks between 120 and $150 \mu \mathrm{m}$ (Table 2).

\begin{tabular}{|c|c|}
\hline & Arvicola terrestris \\
\hline Prevalence $^{\mathrm{a}}$ & $2 / 93(2.2 \%)$ \\
\hline Cysts overall & $74^{\mathrm{c}}$ \\
\hline Intensity $^{\mathrm{b}}$ & $31-43(37 \pm 8.49)$ \\
\hline Cyst length $(\mathrm{mm})^{\mathrm{b}}$ & $1.5-4.5(3.2 \pm 0.64)$ \\
\hline Cyst width $(\mathrm{mm})^{\mathrm{b}}$ & $1-2(1.5 \pm 0.4)$ \\
\hline Hooks ${ }^{b}$ & $28-36(31.1 \pm 2.47)$ \\
\hline Large hooks $(\mu \mathrm{M})^{\mathrm{b}}$ & $150-192(177 \pm 11.76)$ \\
\hline Small hooks $(\mu \mathrm{M})^{\mathrm{b}}$ & $120-150(137 \pm 9.5)$ \\
\hline
\end{tabular}

\section{Discussion}

In this study the relations of sex, weight and length of 318 common voles (22 infected with T. taeniaeformis) and 93 water voles (30 infected with $T$. taeniaeformis) to infestations with this metacestode were analysed with biostatistical methods.

The examined water voles presented body weights between 37.3 and $139 \mathrm{~g}$. Water voles infected with metacestodes of T. taeniaeformis had a mean body weight of $82.1 \mathrm{~g}(\mathrm{n}=2$ 9; Standard Deviation $=16.3$; Standard Error Mean $=2.5$ ), whereas uninfected water voles had a mean body weight of $73.5 \mathrm{~g}(\mathrm{n}=64$; Standard Deviation $=19.6$; Standard Error Mean $=3$ ). Common voles presented body weights between 6.2 and $35.8 \mathrm{~g}$. Non-infected $M$. arvalis had a mean body weight of $17.9 \mathrm{~g}(\mathrm{n}=296$; Standard Deviation $=4.5$; Standard Error Mean $=0.2$ ), whereas those infected with $T$. taeniaeformis metacestodes had a mean weight of $21.3 \mathrm{~g}$ (n $=22$; Standard Deviation $=5.6$; Standard Error Mean $=$ 1.2). Significant differences between non-infected and infected common voles and water voles were found re- garding the body mass ( $\mathrm{p}$ value $=0.045$ for $A$. terrestris, $\mathrm{p}$ value $<0.001$ for $M$. arvalis) (Fig. 1).

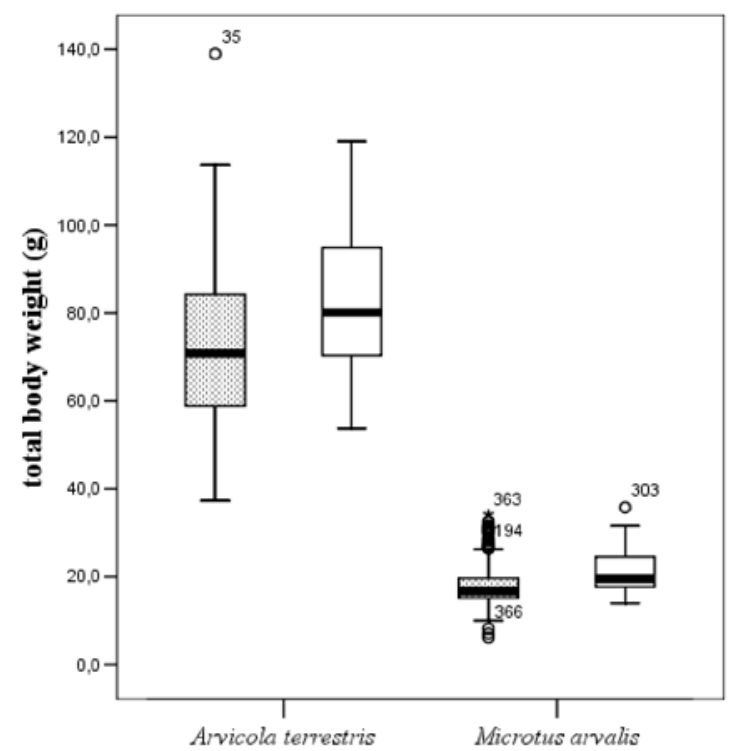

Fig. 1. Boxplots of total body weight distributions of captured Arvicola terrestris and Microtus arvalis populations. Each with Taenia taeniaeformes infestation (left dotted boxplot) and without infestation (right blank boxplot) respectively.

Water voles presented body lengths between 177 and 255 $\mathrm{mm}$. Uninfected voles had a mean length of $204.5 \mathrm{~mm}(\mathrm{n}=$ 64; Standard Deviation $=21.3$; Standard Error Mean $=$ 2.7). Voles infected with $T$. taeniaeformis presented a mean body length of $199 \mathrm{~mm}(\mathrm{n}=29$; Standard Deviation $=36.4$; Standard Error Mean = 6.8). Common voles had body lengths between 79 and $190 \mathrm{~mm}$. Uninfected common voles had a mean body length of $122.5 \mathrm{~mm}(\mathrm{n}=296$; Standard Deviation $=14$; Standard Error Mean $=0.8$ ), whereas those common voles infected with metacestodes presented a mean body length of $127 \mathrm{~mm}(\mathrm{n}=22$; Standard Deviation $=15.1$; Standard Error Mean = 3.2). No significant differences between non-infected and infected voles were found regarding body length (Fig. 2).

With water voles we observed a sex ratio of $35 \%$ male to $65 \%$ female voles. Wieland (1973) reported a gender ratio of one to one at the birth of water voles. At high population densities competition and migration leads to a decrease in male water voles. These circumstances make it obvious that the population densities in the examined areas were high. Out of 93 examined $A$. terrestris $12(36.4 \%)$ male and $17(28.3 \%)$ female voles were infected with metacestodes of $T$. taeniaeformis.

We observed a sex ratio of $52.5 \%$ male and $47.5 \%$ female among the common voles. Stein (1957) reported a sex ratio of $53 \%$ female embryos under laboratory conditions. Furthermore metacestodes of $T$. taeniaeformis were found in $13(7.8 \%)$ male and nine (6\%) female common voles and no relation between the gender and infestations with $T$. taeniaeformis were observed. The range of samples of infected $M$. arvalis voles was too small. 


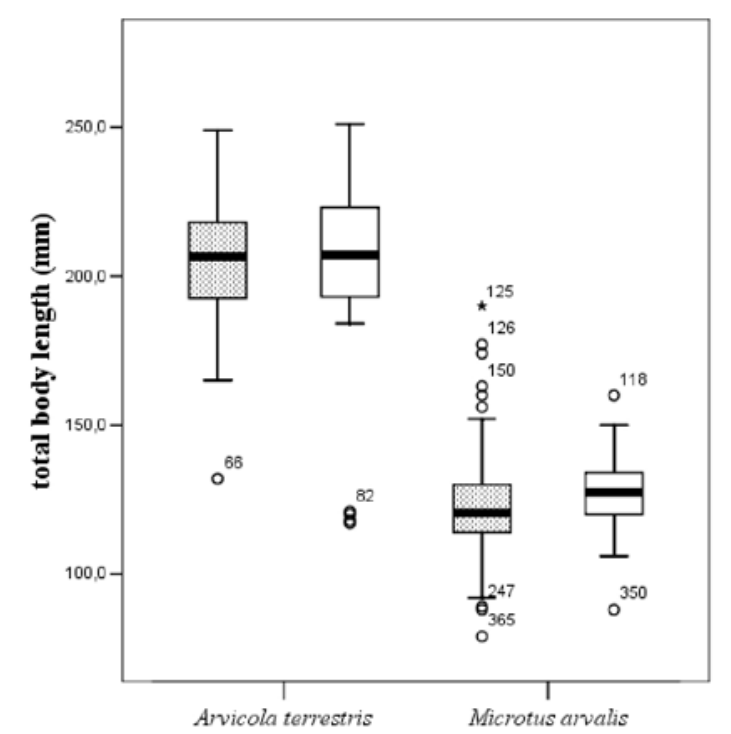

Fig. 2. Boxplots of total body length distributions of captured Arvicola terrestris and Microtus arvalis populations. Each with Taenia taeniaeformes infestation (left dotted boxplot) and without infestation (right blank boxplot) respectively.

No significant differences regarding sex and infections with $T$. taeniaeformis were found in murides in previous studies (e.g. Theis \& Schwab, 1992). However, several studies reported significant differences between infected and non-infected rodents regarding body weight, age, total lengths and abdomen circumferences (e.g. Kowal et al., 2010). It is documented that the youngest mice are not infected with this metacestode (Loos-Frank, 1987). Tenora et al. (1979) only found Taenia metacestodes among bank voles (Myodes glareolus) older than three months. A recent study conducted in Switzerland documented that water voles older than five months were approximately two times more frequently infected than animals younger than three months (Burlet et al. 2011). This is caused by the fact that metacestodes need about two months after infection to become visible.

The results of this study can be summarised as follows: Both $T$. taeniaeformis and $T$. crassiceps could be found in Vorarlberg (Western Austria). Cysts, strobilae and hooks of $T$. taeniaeformis were larger in water voles than in common voles. Furthermore we documented a significant difference between uninfected individuals and those infected with $T$. taeniaeformis regarding body weight, whereas no significant differences were observed regarding body size or sex.

\section{Acknowledgements}

We would like to thank Daniel Ross for proofreading. Furthermore we gratefully acknowledge the excellent technical assistance of Julia Walochnik, Jacek Pietrzak, Susanne Glöckl and Iveta Häfeli.

\section{Ethical standards}

All voles were caught in 2004 in accordance with the Vorarlberger provincial law as published in $\mathrm{Lg}$. Bl. Nr. $50 / 2002$.

\section{Conflict of interest}

The authors declare that they have no conflict of interest.

\section{References}

Arocker-Mettinger, E., Huber-Spitzy, V., Auer, H., GrABNer, G., STUR, M. (1992): Taenia crassiceps in the anterior chamber of the human eye. A case report. Klin. Monbl. Augenheilkd., 201(1): 34 - 37 (In German)

Burlet, P., Deplazes, P., Hegglin, D. (2011): Age, season and spatio-temporal factors affecting the prevalence of Echinococcus multilocularis and Taenia taeniaeformis in Arvicola terrestris. Parasit. Vectors, 4: 6. DOI: 10.1186/1756-3305-4-6

Chermette, R., Bussieras, J., Marionneau, J., Boyer, E., Roubin, C., Prophette, B., Maillard, H., Fabiani, B. (1995): Invasive cysticercosis due to Taenia crassiceps in an AIDS patient. Bull. Acad. Natl. Med., 179(4): $777-$ 780; discussion 780 - 783. (In French)

Delvalle, B. (1989): Larvae of Taenia crassiceps (Cestoda): host specifity and localisation. Parasitol. Res., 76(2): $181-182$

EKanayake, S., Warnasuriya, N. D., SAmarakoon, P. S., Abewickrama, H., Kuruppuarachchi, N. D., DisSANAIKE, A.S. (1999): An unusual 'infection' of a child in Sri Lanka, with Taenia taeniaeformis of the cat. Ann. Trop. Med. Parasitol., 93(8): 869 - 873

FÜHRER, H. P., SchneIder, R., WAlOchnik, J., AUER, H. (2010): Extraintestinal helminths of the common vole (Microtus arvalis) and the water vole (Arvicola terrestris) in Western Austria (Vorarlberg). Parasitol. Res., 106(4): 1001 - 1004. DOI: 10.1007/s00436-010-1753-x

Garin, G. F. J., GALÁn-Puchades, T.G., Moulignier, A., Robert, G., Herán, F., Polivka, M., Olson, P. D., Lorenzo, F., Derouin, F., Conn, D. B. (2005): Case Report: Human Brain Abscess due to a Tetra-Acetabulate Plerocercoid Metacestode (Cyclophyliidea). Am. J. Trop. Med. Hyg., 72(5): $513-517$

Klinker, H., Tintelnot, K., Joeres, R., Muller, J., Gross, U., SchmidT-RotTe, H., LANDWEHR, P., RICHTER, E. (1992): Taenia crassiceps infection in AIDS. Dtsch. Med. Wochenschr., 117(4): 133 - 138 (In German)

Kocher, T. D., Thomas, W. K., Meyer, A., EdWARds, S. V., PÄÄBO, S., VillablanCA, F. X., Wilson, A. C. (1989): Dynamics of mitochondrial DNA evolution in animals: amplification and sequencing with onserved primers. Proc. Natl. Acad. Sci. USA, 86(16): 6196 - 6200

Kowal, J., Nosat, P., AdAMczyK, I., Kornaś, S., 
WAJDZIK, M., TOMEK, A. (2010) [The influence of Taenia taeniaeformis larval infection on morphometrical parameters of muskrat (Ondatra zibethicus)]. Wiad. Parazytol., 56(2): 163 - 166. (In Polish)

LANGLEY, R., FAIRLEY, J.S. (1982): Seasonal variations in the infestations of parasites in a Wood mouse Apodemus sylvaticus population in the West of Ireland. J. Zool., 198: $249-261$

Loos-Frank, B., Zeyhle, E. (1981): Zur Parasitierung von 3603 Rotfüchsen in Württemberg. Z. Jagdwiss., 27: $258-266$

LoOs-Frank, B., Zeyhle, E. (1982): The intestinal helminths of the red fox and some other carnivores in southwest Germany. Z. Parasitenkd., 67(1): 99 - 113

LOOS-FRANK, B. (1987): Larval cestodes in southwest German rodents. Z. Angew. Zool.,74: 97 - 105

Milazzo, C., Ribas, A., Casanova, J. C., Cagnin, M., GERACI, F., DI BELlA, C. (2010): Helminths of the brown rat (Rattus norvegicus) (Berkenhout, 1769) in the city of Palermo, Italy. Helminthologia. 47 (4): 238 - 240. DOI: $10.2478 / \mathrm{s} 11687-010-0037-4$

NeCHAY, G. (1973): Seasonal incidence of larval Hydatigera taeniaeformis infection of Microtus arvalis in Hungary. Parasitol. Hung., 6: 117 - 129

NiETHAMMER, J., KRAPP, F. (1978): Handbuch der Säugetiere Europas. Vol. 1. Rodentia: 305

PÉTAVy, A. F., Tenora, F., Deblock, S. (2003): Co-occurrence of metacestodes of Echinococcus multilocularis and Taenia taeniaeformis (Cestoda) in Arvicola terrestris (Rodentia) in France. Folia Parasitol., 50(2): 157 - 158

PFeIfFER, F., KuschFeldT, S., STOYE, M. (1997): Helminth fauna of the red fox (Vulpes vulpes Linne 1758) in south Sachsen-Anhalt--1: Cestodes. Dtsch. Tierarztl. Wochenschr., 104(10): 445 - 448

REICHENOW, E. (1969): Leitfaden zur Untersuchung der tierischen Parasiten des Menschen und der Haustiere. Leipzig, Germany, Johann Ambrosius Barth, 162 - 163

Rodriguez-Hidalgo, R., Geysen, D., Benítez-Ortiz,
W., Geerts, S., BrandT, J. (2002): Comparison of conventional techniques to differentiate between Taenia solium and Taenia saginata and an improved polymerase chain reaction-restriction fragment length polymorphism assay using a mitochondrial $12 \mathrm{~S}$ rDNA fragment. J. Parasitol., 88(5): 1007 - 1011. DOI: 10.1645/0022-3395(2002) 088[1007:COCTTD]2.0.CO;2

SCHAERER, O. (1987): Die Metacestoden der Kleinsäuger (Insectivora und Rodentia) und ihre Wirtsarten, Verbreitung und Häufigkeit im Kanton Thurgau (Schweiz). Diss, Switzerland, Zürich, Universität Zürich

SCHMIDT, S. (2001): Untersuchungen zum Vorkommen von Capillaria hepatica und Metazestoden der Cyclophyllida bei Wildmäusen in Deutschland. PhD thesis, Germany, Leipzig: Veterinärmedizinische Fakultät, Leipzig

ŠTERBA, J., BLAŽEK, K., BARUŠ, V. (1977): Contribution to the pathology of strobilocercosis (Strobilocercus fasciolaris) in the liver of man and some animals. Folia Parasitol., 24: $41-46$

StEIN, G. H. W. (1957): Materialien zur Kenntnis der Feldmaus Microtus arvalis P. Z. Saugetierkd., 22: 117 - 135

TENORA, F., Wiger, R., BARUŠ, V. (1979): Seasonal and annual variations in the prevalence of helminths in a cyclic population of Clethrionomys glareolus. Holarctic Ecol., 2: $176-181$

THEIS, J.H., SCHWAB, R.G. (1992): Seasonal prevalence of Taenia taeniaeformis: relationship to age, sex, reproduction and abundance of an intermediate host (Peromyscus maniculatus). J. Wildl. Dis., 28(1): $42-50$

WIELAND, H. (1973): Beiträge zur Biologie und zum Massenwechsel der Großen Wühlmaus (Arvicola terrestris L.). Jena, Germany. Zoologische Jahrbücher - Abteilung für Systematik, Ökologie und Geographie der Tiere, 100 (3): $351-428$

Wünschmann, A, Garlie, V, Averbeck, G, Kurtz, H, HoberG, E. P. (2003): Cerebral cysticercosis by Taenia crassiceps in a domestic cat. J. Vet. Diagn. Invest., 15(5): $484-488$ 